\title{
PRODUÇÃO DE MOLIBDÊNIO METÁLICO DE ALTA PUREZA A PARTIR DE SULFETO DE MOLIBDÊNIO NATURAL
}

\author{
A.C. SOUZA ${ }^{1}$ e L.R.P. DE ANDRADE LIMA ${ }^{2}$ \\ ${ }^{1}$ Universidade Federal da Bahia, Programa de Pós-Graduação em Engenharia Industrial \\ ${ }^{2}$ Universidade Federal da Bahia, Departamento de Ciência e Tecnologia dos Materiais \\ E-mail para contato: lelo@ufba.br
}

Resumo - A produção do molibdênio metálico envolve fragmentação e separação de sulfeto de molibdênio (molibdenita) por flotação seguido de ustulação visando à produção de óxido de molibdênio, que é lixiviada por hidróxido de amônia. O molibdato resultante é precipitado por acidificação e após aquecimento é degradado resultando óxido de molibdênio de alta pureza. A redução com hidrogênio deste óxido gera o molibdênio metálico. Neste estudo esta rota foi aplicada para o sulfeto de molibdênio natural que ocorre na região de Carnaíba (BA). A amostra do sulfeto de molibdênio natural apresentou um teor de molibdênio de $48 \% \mathrm{~A}$ recuperação da lixiviação foi de $90 \%$ e os molibdatos gerados com a acidificação do licor apresentaram uma forma prismática com espessura fina. O óxido formado após o aquecimento dos molibdatos indica boa cristalinidade e elevada pureza. O molibdênio metálico obtido após a redução apresentou uma estrutura porosa e o teor de $99 \%$. O rendimento global do processo foi de $85 \%$.

\section{INTRODUÇÃO}

$\mathrm{O}$ sulfeto de molibdênio natural $\left(\mathrm{MoS}_{2}\right)$ é a principal matéria prima usada para a produção do molibdênio metálico, assim como suas ligas e compostos (Dorfler e Laferty, 1981; Crown, 1994; Prasad et al., 1997). O concentrado da molibdenita pode ser obtido através da rota convencional que envolve fragmentação e separação da molibdenita por flotação, sobretudo como subproduto da produção de sulfetos de cobre.

As propriedades do molibdênio são freqüentemente exploradas como revestimentos para aumentar a resistência térmica dos materiais e diminuir seu desgaste. Diversos tipos de aço de elevada resistência a corrosão contém de 8 a 25\% de molibdênio (Olivares, 2005; Magyar, 2007).

Para a obtenção de molibdênio metálico e compostos de molibdênio de alta pureza são usadas rotas piro e hidrometalúrgicas (Habashi, 1999). A Figura 1 sumariza a rota adotada para a obtenção de produtos de molibdênio de elevada pureza, onde é utilizado ustulação do sulfeto de molibdênio natural, seguida por lixiviação com hidróxido de amônia e redução do óxido de molibdênio com hidrogênio.

A ustulação, a lixiviação e a redução do oxido de molibdênio seguem as reações:

$$
\mathrm{MoS}_{2}+7 / 2 \mathrm{O}_{2} \rightarrow 2 \mathrm{SO}_{2}+\mathrm{MoO}_{3}
$$




$$
\begin{aligned}
& \mathrm{MoO}_{3}+2 \mathrm{OH}^{-} \rightarrow \mathrm{MoO}_{4}{ }^{2-}+\mathrm{H}_{2} \mathrm{O} \\
& \mathrm{MoO}_{3}+\mathrm{H}_{2} \rightarrow \mathrm{MoO}_{2}+\mathrm{H}_{2} \mathrm{O} \\
& \mathrm{MoO}_{2}+2 \mathrm{H}_{2} \rightarrow \mathrm{Mo}+2 \mathrm{H}_{2} \mathrm{O}
\end{aligned}
$$

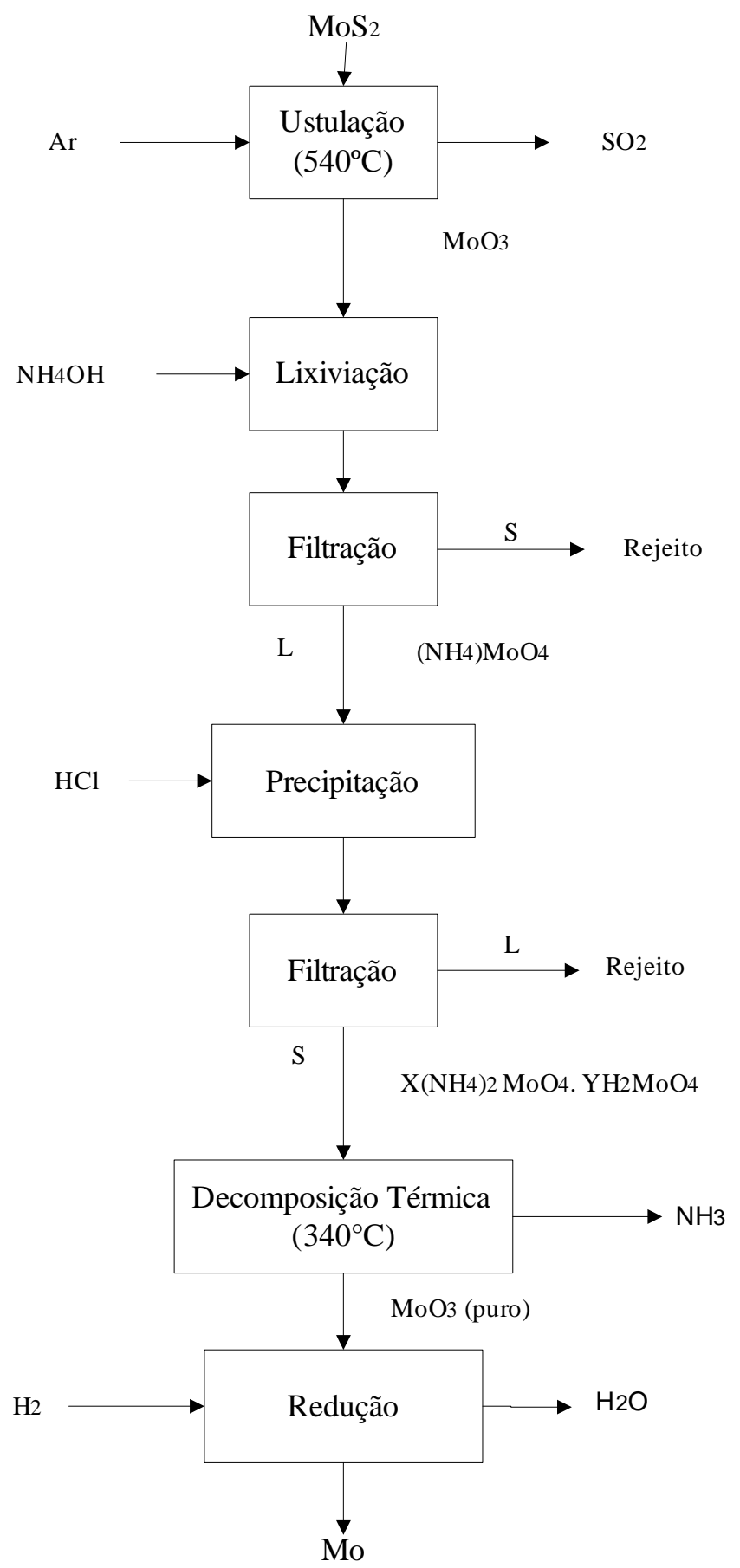

Figura 1 - Fluxograma da produção do molibdênio metálico. 


\section{MATERIAIS E MÉTODOS}

Inicialmente o sulfeto de molibdênio natural foi fragmentado, classificado e ustulado a $540^{\circ} \mathrm{C}$. A lixiviação ocorreu a $24^{\circ} \mathrm{C}$ por 1 hora, com uma solução com excesso estequiométrico de $\mathrm{NH}_{4}(\mathrm{OH})$, para garantir a realização da reação em uma polpa com $31 \%$ de sólidos, em um recipiente parcialmente fechado para evitar evaporação. Foi utilizado um agitador magnético modelo, RH-KT/C com uma agitação suficiente para manter o minério em suspensão.

Após a lixiviação a polpa foi filtrada e o rejeito foi lavado com água destilada até $\mathrm{pH}$ neutro, o material foi posteriormente seco a $60^{\circ} \mathrm{C}$. Em seguida, o licor da lixiviação foi acidificado com $\mathrm{HCl}$ até alcança $\mathrm{pH}$ entre 1 e 2, visando a precipitação dos molibdatos de amônia, o precipitado foi filtrado, seco e aquecido $340^{\circ} \mathrm{C}$, visando a degradação dos molibdatos e formação de óxido de molibdênio que posteriormente foi reduzido em uma atmosfera de hidrogênio em um forno tubular CARBOINE modelo, STF 16/180 na faixa de temperatura de 200 a $955^{\circ} \mathrm{C}$, visando à redução do óxido de molibdênio e formação do molibdênio metálico (Kunda, 1965).

O sulfeto de molibdênio natural foi analisado por ativação neutrônica e o minério ustulado foi lixiviado e o rejeito foi analisado por fluorescência de raios X.

\section{RESULTADOS E DISCUSSÃO}

O sulfeto de molibdênio natural apresentou 38\% de molibdênio os demais elementos em maior proporção são: $\mathrm{Mg}$ com 1,80\%, Al com 1,20\%, K com 1,10\%, seguindo por Fe com $0,71 \%$ e Si com menos de $5 \%$. A figura 2 mostra a superfície do cristal natural com micas.

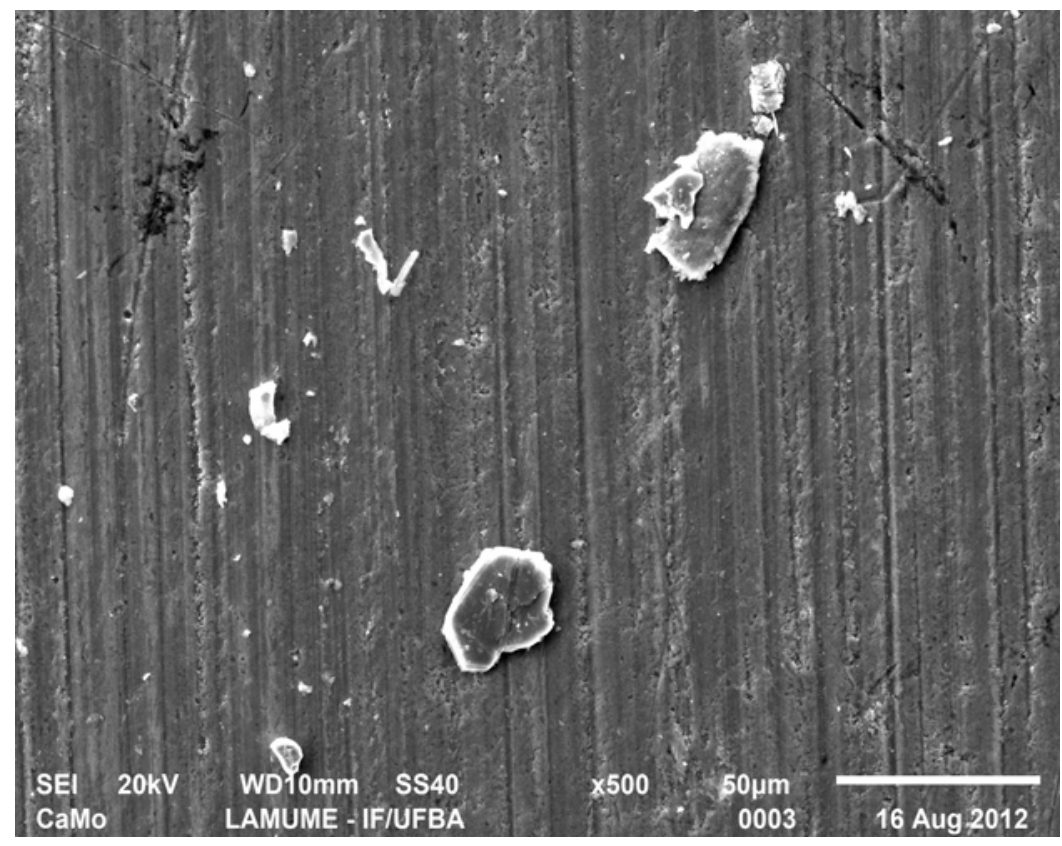

Figura 2 - Imagem em elétrons secundário do cristal de molibdenita natural. 
Após a ustulação do sulfeto de molibdênio natural, o teor de molibdênio na amostra passou a ser de $48 \%$ devido a redução da massa com eliminação do $\mathrm{SO}_{2}$. O rejeito da lixiviação apresentou a seguinte composição: 4,35\% de Fe; 2,02\% de K; 1,72\% de Ca e 1,31\% de Mo que indica uma dissolução de $99 \%$ de Mo. A figura 3 mostra uma fração do rejeito feita no microscópio eletrônico de varredura, em elétrons secundários. Nota-se que esta fração é composta essencialmente pelos demais elementos que se encontram em maior proporção na amostra. Através da imagem e sabendo-se a composição do minério observa-se que o rejeito é composto por micas cujo tamanho apresenta significativa variação que em geral não se apresentam sobrepostas tais como: moscovita, flogopita e biotita.

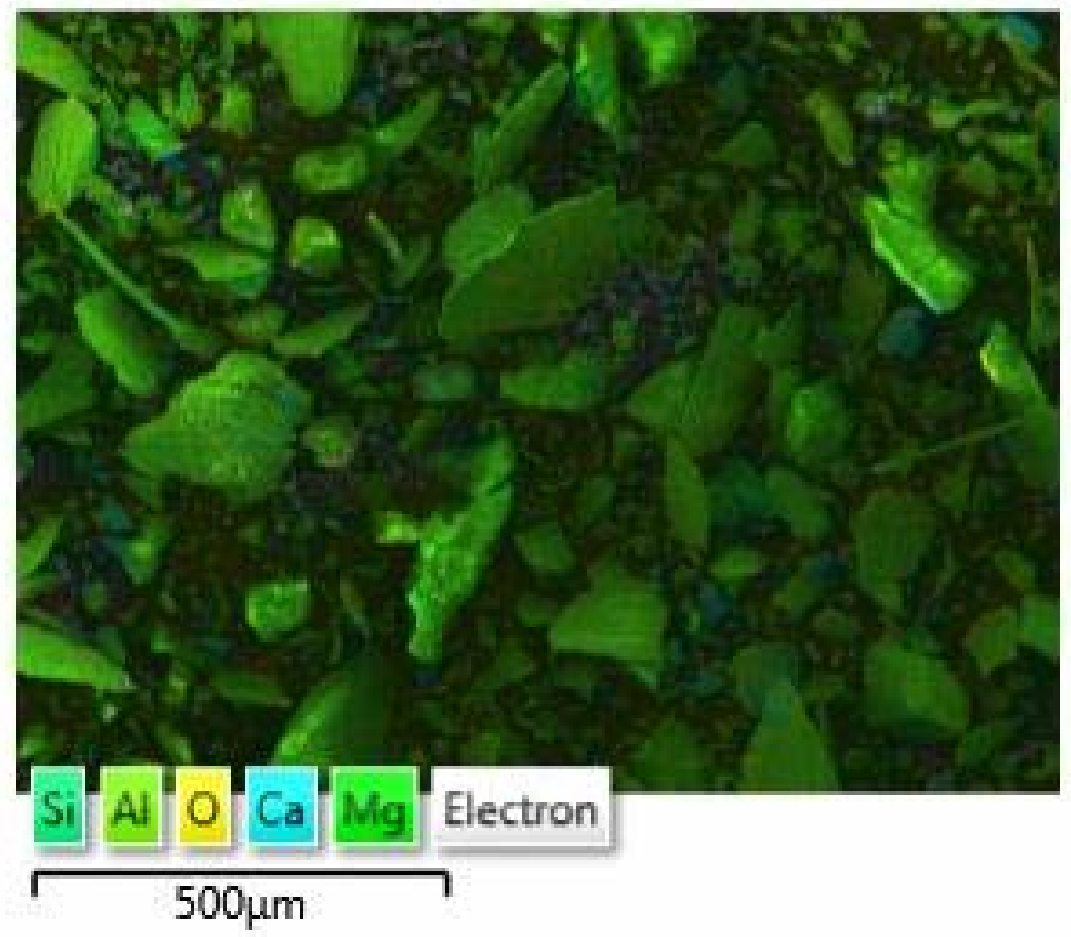

Figura 3 - Imagem em elétrons secundário do rejeito da lixiviação.

O licor da lixiviação foi tratado com $\mathrm{HCl}$, gerando um precipitado de molibdatos de amônia, a análise deste material indicou um conteúdo de $69 \%$ de molibdênio. O comportamento térmico do molibdato de amônia foi avaliado através de análise termogravimétrica. A curva ilustrada na Figura 4 indica a presença de 2 regiões de perda de massa. A primeira região ocorre em uma temperatura de até $400^{\circ} \mathrm{C}$ com uma redução de $15 \%$ da massa referente à decomposição do molibdato e formação de óxido de molibdênio. A segunda região ocorre em aproximadamente $800^{\circ} \mathrm{C}$ devido à sublimação do óxido de molibdênio.

Após a decomposição térmica do molibdato foi produzido o óxido de molibdênio. A difração de raios-X do óxido de molibdênio formado (figura 5). Os picos identificados pelos padrões de referência fornecidos pelo ICDD (International Centre for Diffraction Data) foram comparados com o padrão RRUFF e indica que o óxido produzido tem boa cristalinidade e pureza elevada. 


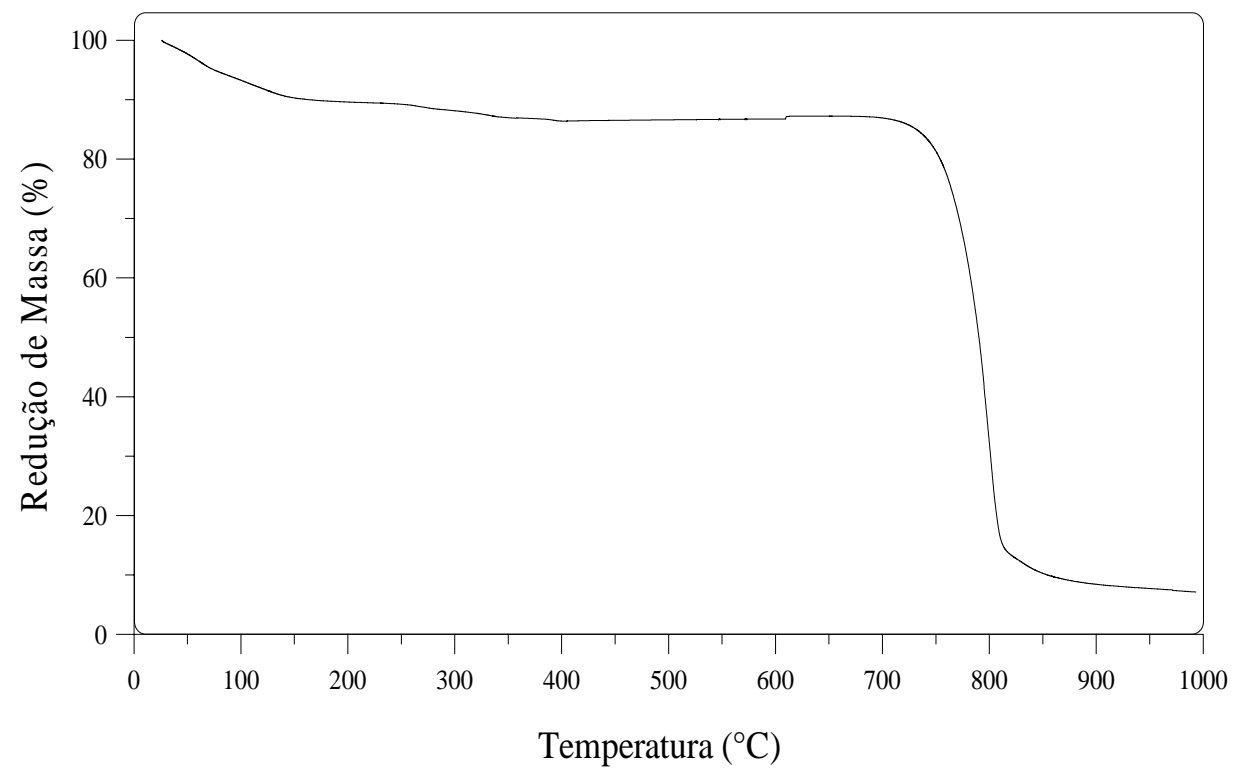

Figura 4 - Análise termogravimétrica do molibdato de amônia.

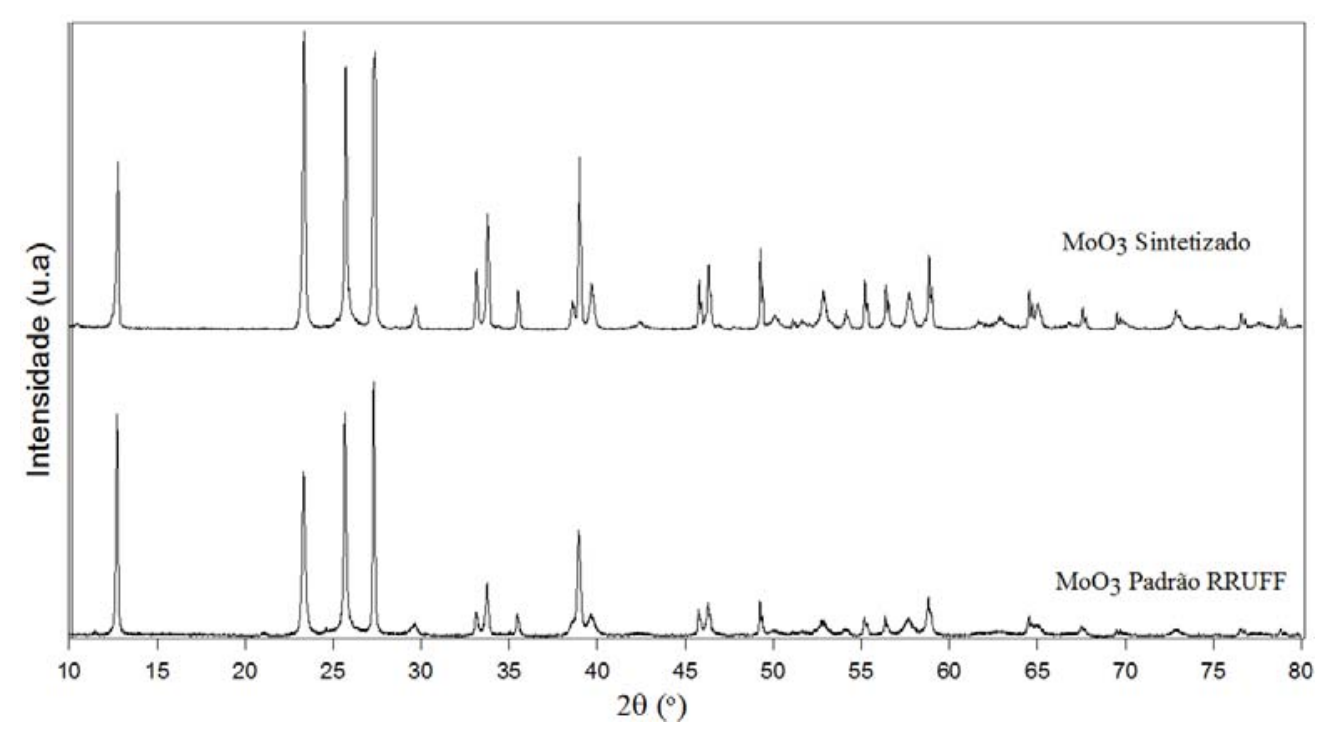

Figura 5 - Difratograma do óxido de molibdênio.

A figura 6 apresenta a imagem do óxido de molibdênio em elétrons secundários, onde pode ser observada a forma de prismas, alongados com tamanhos variados, e em geral espessura fina (Kennedy e Bevans, 1974). A fração analisada indica prismas com tamanhos de até 22,77 micra.

Para a produção do metal foi utilizado o óxido de molibdênio obtido na lixiviação com hidróxido de amônia (Figura 7a). Foi produzido molibdênio metálico (Figura 7b) com teor de 99\% de molibdênio. 


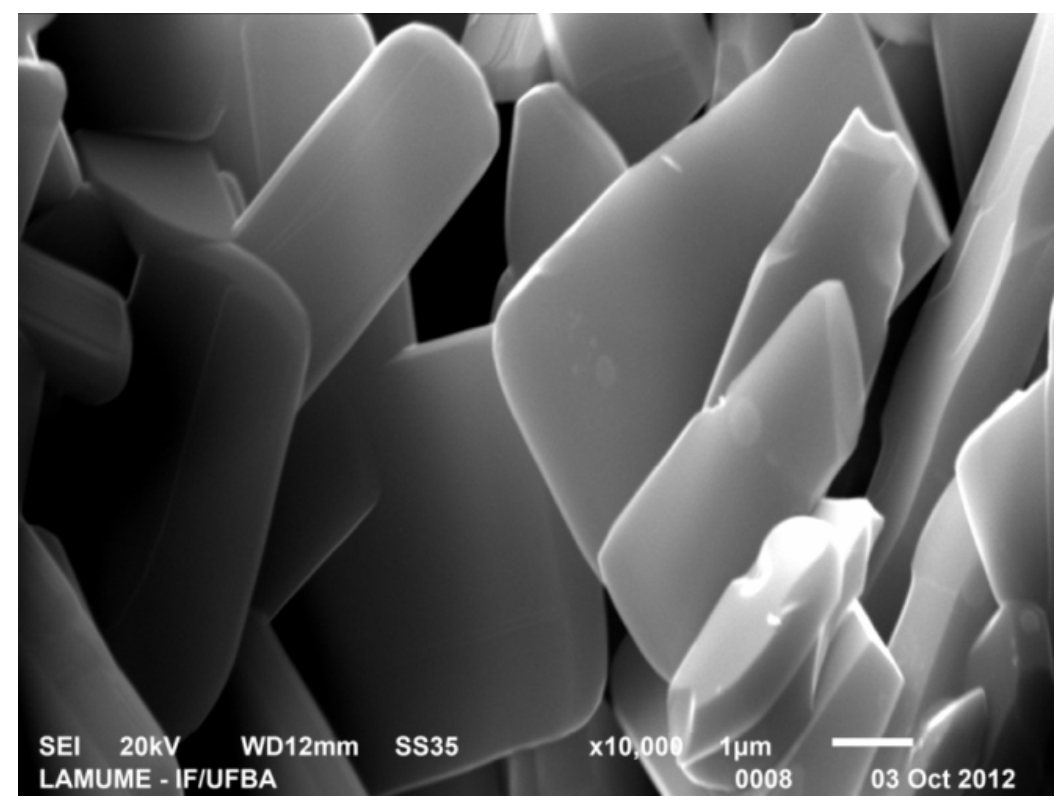

Figura 6 - Imagem em elétrons secundários do óxido de molibdênio produzido.

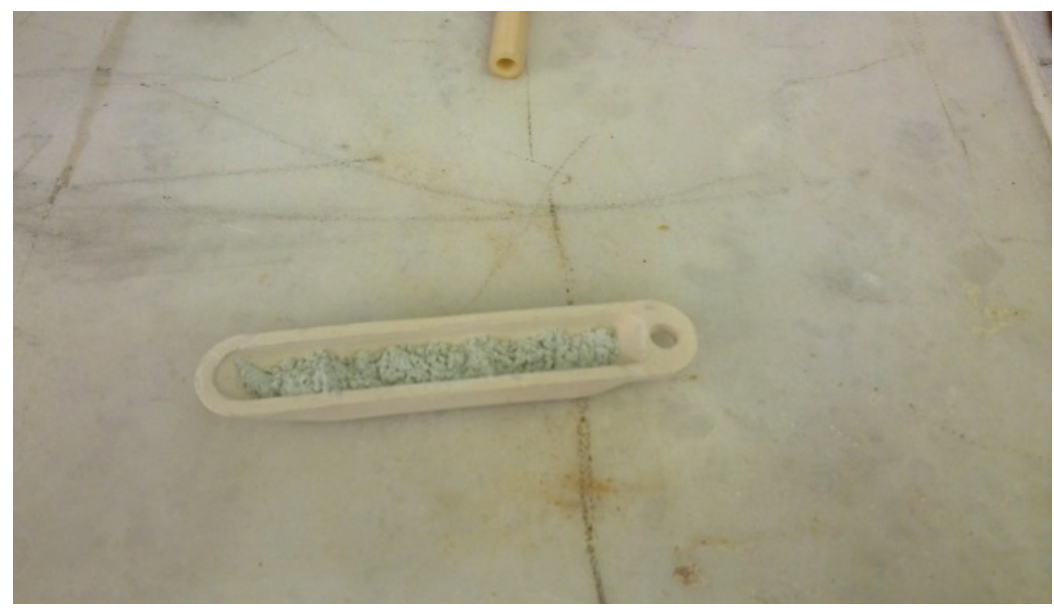

(a)

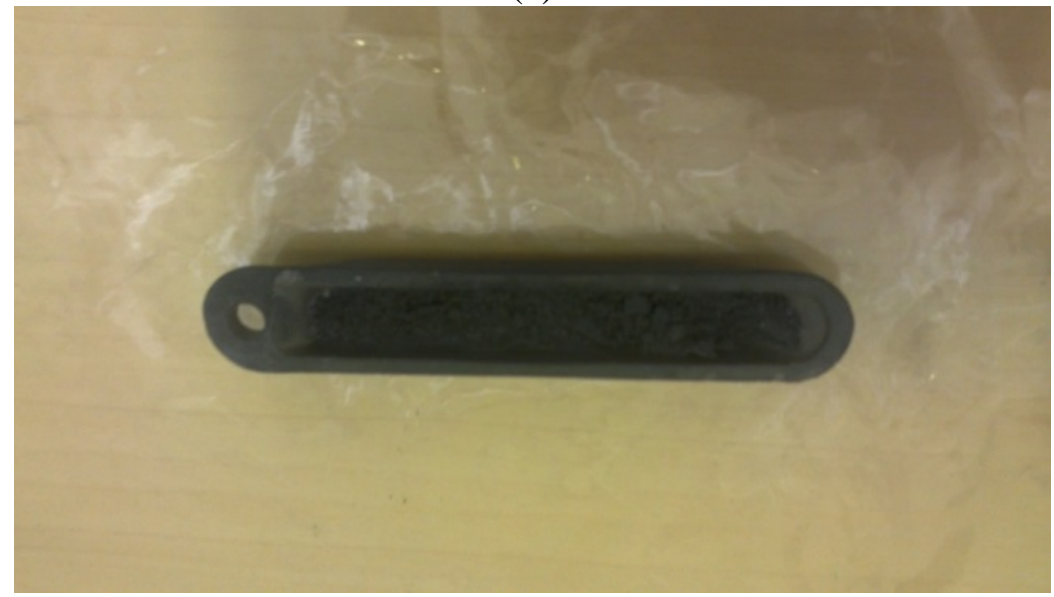

(b)

Figura 7 - a) Navícula de alumina com oxido de molibdênio a ser inserida no forno para redução, b) Navícula de alumina com molibdênio metálico produzido após a redução. 
A figura 8 mostra a imagem em elétrons secundários dos cristais de molibdênio metálico obtidos após a redução do óxido de molibdênio. Durante o processo de redução ocorre injeção de hidrogênio e retirada de oxigênio devido a formação de água em função disto ocorre uma alteração da estrutura prismática. Nota-se que o molibdênio metálico produzido apresenta estrutura porosa.

As perdas no processo durante a produção dos molibdatos de amônia forma de apenas $14,96 \%$ visto que a dissolução obtida foi de $89 \%$. O rendimento do processo até a obtenção do metal foi de $90 \%$ as perdas possivelmente estão associadas a erros de medição.

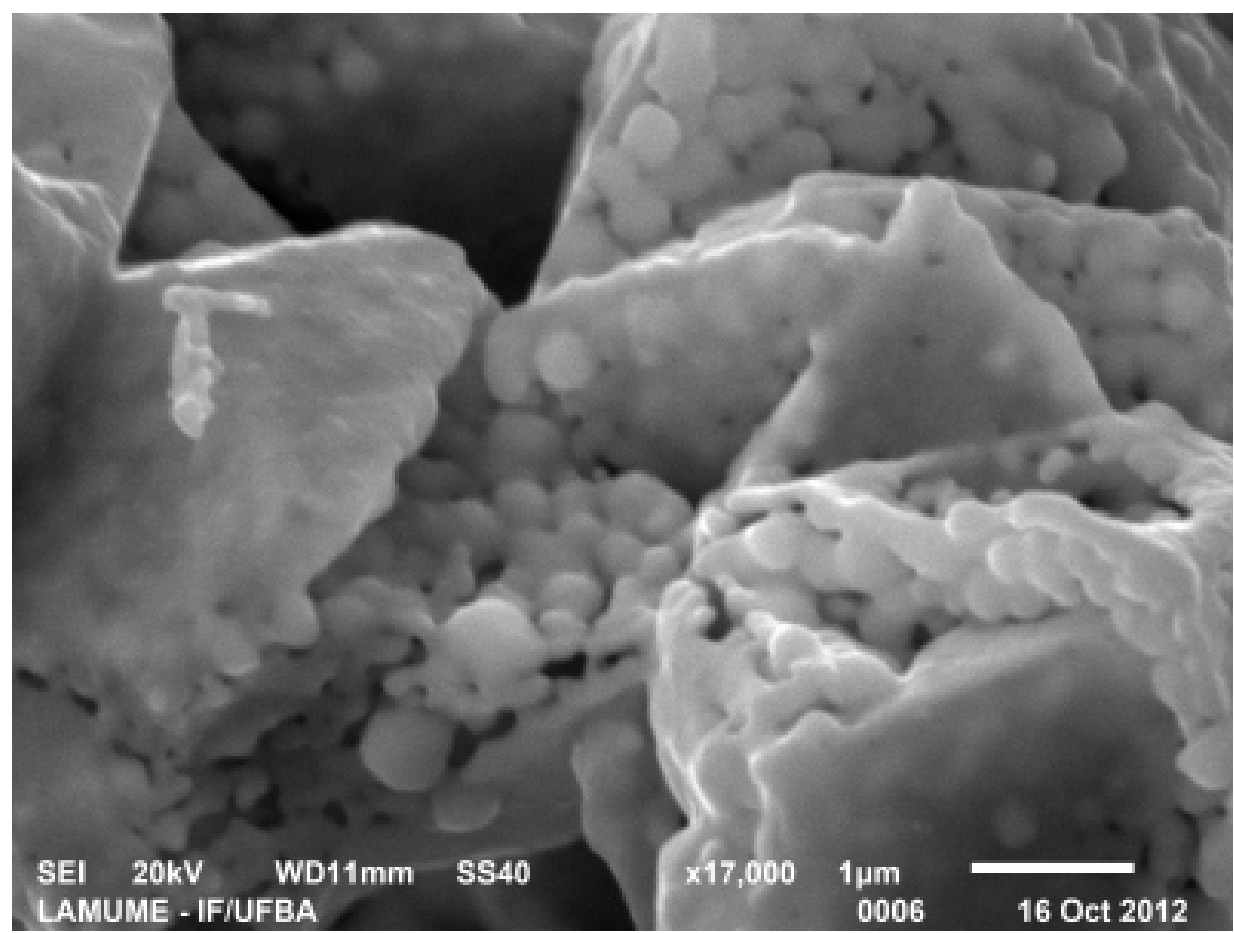

Figura 8 - Imagem em elétrons secundários do molibdênio metálico.

\section{CONCLUSÕES}

Neste trabalho é apresentado o tratamento do sulfeto de molibdênio natural da região de Carnaíba- BA visando a produção de molibdênio metálico. O sulfeto de molibdênio natural apresentou um teor de $38 \%$ de Mo e aproximadamente $10 \%$ de micas. O experimento se inicia com a ustulação do sulfeto de molibdênio natural e posterior lixiviação com $\mathrm{NH}_{4} \mathrm{OH}$ seguida por redução com hidrogênio. A amostra ustulada apresentou um teor de $48 \%$ de Mo devido à redução da massa causada pela formação de $\mathrm{SO}_{2}$. Após a lixiviação o rejeito apresentou 3,97\% de Mo o que indica uma dissolução de 89\% Mo. Os molibdatos de amônia gerados com a acidificação do licor apresentaram uma forma de prismática com tamanhos variados e espessura fina. O óxido formado após o aquecimento dos molibdatos indica boa cristalinidade e elevada pureza. O molibdênio metálico obtido após a redução apresentou uma estrutura porosa devido à retirada do oxigênio e à formação da água. O teor do molibdênio produzido foi de $99 \%$ o rendimento geral do processo foi de $85 \%$. 


\section{AGRADECIMENTOS}

O Conselho Nacional de Desenvolvimento Cientifico e Tecnológico (CNPq) é agradecido pelo suporte financeiro a este estudo através do projeto número 550294/2011-2 e de bolsa de pesquisador para L.R.P. de Andrade Lima (projeto número: 302024/2011-5). A Coordenação de Aperfeiçoamento de Pessoal de Nível Superior (CAPES) e o Programa de Pós-Graduação em Engenharia Industrial da Universidade Federal da Bahia são agradecidos pela concessão de uma bolsa de mestrado para A.C. Souza. O laboratório do Grupo de Processos e Tecnologia (PROTECUFBA) é agradecido pela realização da difração de raios X. O Laboratório de Microscopia Eletrônica (LAMUME) é agradecido pela realização das imagens das amostras.

\section{REFERÊNCIAS}

CROWN, P., Statistics and analysis of worlds mineral industry. Mineral Year Book. McMillan Press Ltd, London, pp. 176 -181, 1994.

DORFLER, R. R.; LAFERTY, J.M., Review of molybdenum recovery processes. Journal of Metals, v.33, 48-53, 1981.

HABASHI, F., Textbook of hydrometallurgy, Second Edition, Métallurgie Extractive Québec, 1999.

KENNEDY, M. J.; BEVANS, C., A kinetic study of the reduction of molybdenum trioxide by hydrogen, Journal of the Less-Common Metals, v. 36, p.23-30, 1974.

KUNDA, V., Molybdenum recovery process, U.S. Patent 3,196,004, 1965.

MAGYAR, M. J., Molybdenum, Minerals Yearbook, USGS, 2007.

OLIVARES, G., Mercado nacional e internacional del molibdênio, Comision Chilena Del Cobre, 2005.

PRASAD, P. M.; MANKHAND, T.R.; PRASAD, A. J. K. Molybdenum extraction processes: an overview. NML Technical Journal , v.39, 39-58, 1997.

SOUZA, A.C.; DE ANDRADE LIMA, L.R.P. Produção de molibdênio metálico a partir da molibdenita de Carnaíba (Bahia). Anais do XXV Encontro Nacional de Tratamento de Minérios e Metalurgia Extrativa, p. 438-445, 2013. 